

\title{
Effect of exercise on basal insulin levels in normoglycaemic offspring of patients with Type 2 Diabetes mellitus
} Taiwo EO ${ }^{* 1}$, Sofola $\mathrm{OA}^{2}$, Fasanmade $\mathrm{AA}^{3}$, Onyemelukwe $\mathrm{G}^{4}$

1Department of Physiology, Olabisi Onabanjo University, Ago-Iwoye, Ogun State, Nigeria ${ }^{2}$ Department of Physiology, College of Medicine, University of Lagos, Idi-Araba, Lagos, Nigeria 3Department of Physiology, University of Ibadan, Ibadan, Oyo State, Nigeria ${ }^{4}$ Department of Medicine, Ahmadu Bello University Teaching Hospital, Zaria, Nigeria

\footnotetext{
*Correspondence: Dr. EO Taiwo, Department of Physiology, Olabisi Onabanjo University, Ago-Iwoye, Ogun State, Nigeria. Email: taiwobmc2010@yahoo.com; olagboye.taiwo@oouagoiwoye.edu.ng; ORCID - https://orcid.org/0000-0003-4213-0930
}

\begin{abstract}
Background: Low basal insulin level is a risk factor for Type 2 Diabetes mellitus (T2DM) as a result of altered insulin sensitivity pattern. However, it is uncertain if exercise may influence the occurrence of T2DM in the offspring of diabetic parents.

Objective: To assess the effect of exercise on basal insulin levels in the offspring of T2DM parents compared with the offspring of non-diabetic parents.

Design: The participants were assigned into four groups using a convenience sampling method; 27 Normal-weight Offspring of Non-Diabetic Parents (NONDP), 21 Normal-weight Offspring of Diabetic Parents (NODP), 26 Overweight Offspring of Non-Diabetic Parents (OONDP) and 21 Overweight Offspring of Diabetic Parents (OODP). Each participant followed a protocol of graded exercise using "tummy trimmer" everyday spending 30-45 minutes daily for 24 weeks. Blood samples were obtained after overnight fasting for determination of insulin level using standard methods (immunoassay technique) at baseline, six weeks, 12 weeks, 18 weeks and 24 weeks respectively.

Results: There were 23/42 males (54.8\%) in the study groups and 34/51 females (64.2\%) in the control groups. Thirty-one $(58.7 \%)$ in the control group and 24 (57.1\%) in the study group were aged 21-30 years. An increase in insulin levels was recorded at 12 weeks in all groups except in NONDP where the insulin levels decreased. The insulin level change was highest in the NODP $(2.25 \mathrm{ng} / \mathrm{ml})$ group.

Conclusions: Graded exercise improved insulin levels in all test groups. The clinical importance of graded exercise in the prevention of diabetes mellitus among the offspring of diabetic parents may be promising.

Keywords: Diabetes mellitus, Graded exercise, Insulin levels, Offspring.
\end{abstract}

\section{Introduction}

Diabetes mellitus is a disorder of intermediary carbohydrate, protein and lipid metabolism. It is characterized by hyperglycaemia, glycosuria, polydipsia, polyuria, polyphagia and weight loss. This condition is associated with secondary alterations in glucose, fat and protein metabolism, leading to many biochemical disorders. These disorders include peripheral 
insulin resistance, impaired regulation of hepatic glucose production with declining $\beta$-cell function and eventual $\beta$-cell failure. [1]

Regular physical activity in individuals with Type 2 Diabetes mellitus (T2DM) is associated with several health benefits, including improved fitness and quality of life, improved insulin sensitivity, reduced lipid levels, and lower rates of micro-and macrovascular complications and mortality. [2] Despite the reported benefits in the management of T2DM, physical exercise remains a challenge for many because of the dysglycaemia that occurs either during or after exercise. Few scientifically rigorous studies have explored how to prevent dysglycaemia from occurring, therefore the evidence-base for patient guidance remains suboptimal. [3]

In health, exercise causes major changes in glucose production and utilization, underpinned by rapid changes in circulating insulin, glucagon, catecholamines and other counterregulatory hormones. Studies in healthy individuals highlight several processes contributing to glucose turnover during exercise. These include mobilization of glucose into exercising skeletal muscle via the upregulation of insulin-dependent- and independent glucose transporters (e.g. GLUT4), [4] and changes in exercise-associated fuel metabolism. [3]

Maintenance of glycaemic control and metabolic homeostasis are the primary objectives for the treatment of T2DM. The current methods of treatment provide effective glycaemic control and metabolic homeostasis for less than five years; this, in most cases, requires multidrug therapies and in some cases, the use of insulin injection to boost the insulin level. [1] Therefore, any process which will increase insulin level will ameliorate the effects of T2DM or delay the onset of T2DM among the offspring in whom increased physical activities and exercise are applicable. [4] This observation is a justification for the present study. Moreover, there is a paucity of literature on the effect of exercise on basal insulin levels among offspring of T2DM, although exercise has been known to ameliorate the effect of DM by improving basal insulin levels. ${ }^{5]}$ Therefore, the objective of this study was to determine the effect of exercise on the basal insulin level of normoglycaemic offspring of patients with T2DM.

\section{Methods}

An experimental, interventional study was carried out on normoglycaemic offspring of patients with T2DM (study group) and normoglycaemic offspring of non-diabetic parents (control group). The parents of the study group attended the Endocrinology Clinic of the University College Hospital ( $\mathrm{UCH})$, Ibadan and Catholic Hospital Oluyoro, Oke-Ofa, Ibadan, South-west, Nigeria. The study group comprised 42 individuals while 53 normoglycaemic offspring of non-diabetic parents aged 25 to 50 years were randomly selected using a convenience sampling method from undergraduate students of the University of Ibadan, South-West, Nigeria. Exclusion criteria for the study group included: offspring who were diabetic or had impaired glucose tolerance (assessed by Fasting Blood Glucose).

The participants $(\mathrm{n}=95)$ were divided into four groups as follows: Group $1-(\mathrm{n}=21)$ overweight / obese offspring of T2DM parents (OODP); Group 2 - $(\mathrm{n}=21)$ normal weight/normal Body Mass Index (BMI) offspring of T2DM parents (NODP); Group 3 $(\mathrm{n}=26)$ overweight/obese offspring of nondiabetic parents (OONDP); Group $4-(\mathrm{n}=27)$ normal weight/normal BMI offspring of nondiabetic parents (NONDP).

Ethical considerations 
The study was approved by the University of Ibadan and University College Hospital Joint Institutional Review Board (UI/UCH Joint IRB) and Catholic Hospital Ethics Committee, before its implementation.

\section{Study Procedure}

The basal insulin level (fasting) was the parameter measured in the study. This refers to background insulin that regulates glucose levels in between meals. It is usually less than $25 \mathrm{ng} / \mathrm{ml}$. Ten millilitres of venous blood was obtained from each subject into plain bottles in the morning after overnight fasting. Separation of serum at $3,000 \mathrm{rpm}$ was carried out at the Institute of Medical Research and Training (IMRAT) of the College of Medicine, University of Ibadan. The serum obtained was stored at temperature not exceeding $-80^{\circ} \mathrm{C}$ for insulin level estimation. Serum insulin level was measured using a Chemilluminescent Microparticle Immunoassay (Abbott Japan Co., $\left.\operatorname{Ltd}^{\circledast}\right)$.

The height of participants was measured using standard hospital adult vertical rule with sliding arms which had been recalibrated and certified by a Biomedical Engineering Technician before use. An Omron ${ }^{\circledR}$ fat estimator was used to measure the weight and BMI after imputing the height of the subject. The study subject stood erect, upright and bare-footed. Extra clothing such as heavy coats and sweaters were removed while the measurements on Omron equipment were being taken. The subject held his stretched hands forward as if he was riding a motor-bike while on the Omron equipment. The readings were appropriately recorded.

Body mass index (BMI) values for the subjects were read off as displayed on the screen of Omron equipment. The BMI values were used to group subjects into two main groups as follows: normal $\mathrm{BMI}=18.5$ to $24.9 \mathrm{~kg} / \mathrm{m}^{2}$ and overweight $/$ obese $=25-29.9 \mathrm{~kg} / \mathrm{m}^{2}$ and $>30.0$ $\mathrm{kg} / \mathrm{m}^{2}$.

Tummy trimmer, a piece of portable lightweight equipment, was selected for the study. It is indoor anaerobic equipment. It is compact and can fit right in the subject's briefcase. During each phase of the exercise, the Tummy trimmer is held on the two handles and the sole of the two feet are put inside the pedal rest while the subject assumes different positions. The subject pulled the tummy trimmer's spring towards himself or herself either while lying flat or sitting up on the floor. The subject was made to sit up with the legs straight, leaned the body backward until completely lying back with the head on the floor. He/she returned to the sitting position in a harmonic fashion. The subject was advised to start slowly and work up to repetitions as she/he felt comfortable harmoniously. The subject was advised to lie flat on the floor, extend the legs straight up in the air while keeping the back on the floor and raise the legs without bending them. The subject was advised to sit erect with the legs straight and raise the handle to tummy level using the arms only. Finally, the subject was advised to lie flat on the floor while bending the knees up to the chest. The subject was to make a circular motion, push the feet up and then round towards the floor again. The different positions were observed for the exercise period of 30 to 40 minutes (a video clip of the exercise procedure was shown to the subjects before the commencement of the exercise). Each subject was advised to undergo the four phases of exercise between 30 and 40 minutes daily (either in the morning or evening) and to contact the researcher on cell phone whenever problems arose with the apparatus. Furthermore, the research assistants made regular cell phone calls to each of the subjects to ensure compliance with an exercise schedule and to keep follow-up appointments every six weeks. 
Data obtained from the venous blood sampling and by anthropometric measurements were recorded at recruitment, and 6, 12, 18 and 24 weeks. The data obtained were analysed using the statistical software (SPSS version 15.0). The difference in variables with statistical probability values $(P)$ less than 0.05 were considered statistically significant.

\section{Results}

Table I shows the age and sex distribution in the study and control groups. There were 23 males
$(54.8 \%)$ in the study groups and 34 females $(64.2 \%)$ in the control groups. Thirty-one (58.7\%) in the control groups and $24(57.1 \%)$ in the study groups were aged 21-30 years. In the OODP group, there were 21 subjects $(22.1 \%)$ out of which 11 (52.4\%) were aged 21-30 years. There were $27(28.4 \%)$ subjects in the NODP group, and $16(59.3 \%)$ of them were aged 21-30 years. Distribution according to sex showed there were $42(44.2 \%)$ males and $53(55.8 \%)$ females. The NODP group comprised $16(76.2 \%)$ males and 5 $(23.8 \%)$ females while the NONDP group comprised $16(59.3 \%)$ males and 11 (40.7\%) females.

Table I: Age and sex distributions of study and control groups

\begin{tabular}{|c|c|c|c|c|c|c|c|c|}
\hline & & $\begin{array}{l}\text { Study Group } \\
\text { n (\%) }\end{array}$ & $\begin{array}{l}\text { Control Group } \\
\text { n (\%) }\end{array}$ & $\begin{array}{l}\text { OODP } \\
\text { n (\%) }\end{array}$ & $\begin{array}{l}\text { NODP } \\
\text { n (\%) }\end{array}$ & $\begin{array}{l}\text { OONDP } \\
\text { n (\%) }\end{array}$ & $\begin{array}{l}\text { NONDP } \\
\text { n (\%) }\end{array}$ & $\begin{array}{l}\text { Total } \\
\text { n (\%) }\end{array}$ \\
\hline \multirow[t]{5}{*}{ Age (years) } & $11-20$ & $8(19.0)$ & $22(41.5)$ & $3(14.3)$ & $5(23.8)$ & $11(42.3)$ & $11(40.7)$ & $30(31.6)$ \\
\hline & $21-30$ & $24(57.1)$ & $31(58.5)$ & $11(52.4)$ & $13(61.9)$ & $15(57.7)$ & $16(59.3)$ & 55 (57.9) \\
\hline & $31-40$ & $6(14.3)$ & $0(0.0)$ & $5(23.8)$ & $1(4.8)$ & $0(0.0)$ & $0(0.0)$ & $6(6.3)$ \\
\hline & $41-50$ & $4(9.5)$ & $0(0.0)$ & $2(9.5)$ & $2(9.5)$ & $0(0.0)$ & $0(0.0)$ & $4(4.2)$ \\
\hline & Total & $42(100.0)$ & $53(100.0)$ & $21(22.1)$ & $21(22.1)$ & $26(27.4)$ & $27(28.4)$ & $95(100)$ \\
\hline \multirow[t]{3}{*}{ Sex } & Male & $23(54.8)$ & $19(35.8)$ & $7(33.3)$ & $16(76.2)$ & $3(11.5)$ & $16(59.3)$ & $42(44.2)$ \\
\hline & Female & $19(45.2)$ & $34(64.2)$ & $14(66.7)$ & $5(23.8)$ & $23(88.5)$ & $11(40.7)$ & $53(55.8)$ \\
\hline & Total & $42(100.0)$ & $53(100.0)$ & $21(22.1)$ & $21(22.1)$ & $26(27.4)$ & $27(28.4)$ & $95(100)$ \\
\hline
\end{tabular}

OODP - Overweight/Obese offspring of diabetic patients; NODP - Normal weight offspring of diabetic patients; OONDP Overweight/Obese offspring of non-diabetic patients; NONDP - Normal weight offspring of non-diabetic patients

Table II shows a progressive increase in mean basal insulin levels of the participants over 24 weeks of exercise programme. The increase in the mean levels of insulin was seen at 12 weeks in all the groups except in NONDP where there was a decrease in the level of insulin. The highest change in insulin levels was seen in NODP $(2.25 \mathrm{ng} / \mathrm{ml})$ while the least change was seen in NONDP $(0.18 \mathrm{ng} / \mathrm{ml})$.

\section{Discussions}

The present study shows that the majority of the participants were aged between 21 and 30 years.
This may be because the study involved the offspring of T2DM and non- diabetic parents who are still very young.

In this study, the progressive increase in the mean levels of insulin in all the groups except in the NONDP group. This observation suggested that exercise using tummy trimmer, facilitated the release of insulin from the $\beta$-cells of the pancreas. The elaboration of insulin would subsequently lower the hyperglycaemia associated with exercise during positive Adenosine Triphosphate (ATP) production to enhance power shift in exercise. This forms an efficient tool for insulin resistance that usually 
predates the development of T2DM by many

years among the offspring of T2DM patients. [5]

Table II: Mean insulin levels in offspring of diabetic and non-diabetic parents before and during six months of exercise

\begin{tabular}{lllllllll}
\hline Group & $\begin{array}{l}\text { Pre-exercise } \\
\text { Insulin } \\
\mathbf{( n g / m l )}\end{array}$ & $\begin{array}{l}\mathbf{6} \text { weeks } \\
\text { Insulin } \\
\mathbf{( n g / m l )}\end{array}$ & $\begin{array}{l}\mathbf{1 2} \text { weeks } \\
\text { Insulin } \\
\mathbf{( n g / m l )}\end{array}$ & $\begin{array}{l}\mathbf{1 8} \text { weeks } \\
\text { Insulin } \\
\mathbf{( n g} / \mathbf{m l})\end{array}$ & $\begin{array}{l}\mathbf{2 4} \text { weeks } \\
\text { Insulin } \\
\mathbf{( n g} / \mathbf{m l})\end{array}$ & $\begin{array}{l}\text { Insulin } \\
\text { level change }\end{array}$ & T & $\boldsymbol{P}$ value \\
\hline OODP & $14.6 \pm 1.2$ & $14.6 \pm 1.2$ & $15.6 \pm 1.3$ & $16.0 \pm 1.3$ & $16.1 \pm 1.3$ & 1.53 & -4.898 & 0.000 \\
NODP & $13.6 \pm 1.0$ & $13.6 \pm 1.0$ & $14.0 \pm 1.1$ & $14.6 \pm 1.3$ & $15.8 \pm 1.2$ & 2.25 & -5.207 & 0.000 \\
OONDP & $14.3 \pm 1.2$ & $14.6 \pm 1.2$ & $15.8 \pm 1.2$ & $15.0 \pm 1.1$ & $15.2 \pm 1.1$ & 0.87 & -4.706 & 0.000 \\
NONDP & $13.4 \pm 1.3$ & $13.4 \pm 1.3$ & $13.3 \pm 1.1$ & $13.3 \pm 1.3$ & $13.3 \pm 1.1$ & -0.18 & 0.453 & 0.654 \\
\hline
\end{tabular}

Mean \pm Standard Error of the Mean (SEM)*Significant at $p<0.05$ level

OODP - Overweight/Obese offspring of diabetic patients; NODP - Normal weight offspring of diabetic patients; OONDP Overweight/Obese offspring of non-diabetic patients; NONDP - Normal weight offspring of non-diabetic patients

This study is similar to the one carried out by Marliss, [9] which showed the effect of intense exercise on insulin release. At this point, it is pertinent to highlight the fact that the present study is the first, as far as we are aware, in which basal insulin level was determined among the offspring of T2DM using tummy trimmer as exercise apparatus. The results obtained in the present study will, therefore, serve as a baseline for comparison with similar studies that may be undertaken in the future.

In the present study, the elaboration of insulin after six months of exercise showed that exercise plays a pivotal role in making insulin available for use in tissues during exercise. In effect, this observation showed that the availability of insulin is an important factor in glucose homeostasis. [3]

Skleryk et al., ${ }^{[8]}$ did not find any beneficial change from five days a week of aerobic exercise at $65 \%$ VO2 peak in overweight/obese sedentary men, but their exercise intervention was only for two weeks, which may not have been of sufficient duration to induce detectable changes. Likewise, this study is similar to the one carried out by Conn et al., [9] and Grieco et al. [10] where active young adults on recreations were studied. The workers found increases in insulin levels in both studies. In the study done by Chen et al., [11] where the participants were studied for compliance with exercise intensity, there were two groups: non-metabolic syndrome group (normoglycaemic) and metabolic syndrome group (diabetics). The former group attained greater exercise compliance and maintained insulin sensitivity, while the latter group displayed poorer exercise compliance, which may have contributed to the decline in insulin sensitivity in them. Exercise volume is a variable that is subject to manipulation in exercise interventions. Malin et al., [12] examined a possible dose-response report of additional benefits from higher exercise doses (>1900 kcal/week), with increases in insulin sensitivity and improved $\beta$-cell functions among adults with pre-diabetes. [12] As part of the limitations of the study, it is instructive to stress that such levels of activity may be desirable but compliance is often low even for much lower exercise volumes. For example, while lowintensity training such as walking for 30 minutes, three to four days per week, for six months, improves markers of glycaemic control, a further six months of higher intensity exercises, for example jogging for three to four days per week for six months elicits substantially greater improvements in basal insulin levels. [12]

\section{Conclusion}

Graded exercise using a tummy trimmer is an important tool for the improvement of basal 
insulin levels. It should be recommended for the offspring of patients with T2DM to delay or prevent the onset of DM.

Acknowledgements: The authors wish to thank everybody who has contributed one way or the other to the success of this article.

Authors' Contributions: TEO conceived and designed the study. TEO and FAA acquired the data, SOA analysed and interpreted the data, TEO drafted the manuscript, OGC and FAA revised the manuscript for sound intellectual content. All the authors approved the final version of the manuscript.

Conflict of interest: None

Funding: Self-funded.

Publication History: Submitted 16 May 2019; Revised 18 August 2019; Accepted 07 September 2019.

\section{References}

1. Bacha F, Lee S, Gungor N, Arslanian S. From pre-diabetes to Type 2 diabetes in obese youth: pathophysiological characteristics along the spectrum of glucose dysregulation. Diabetes Care 2010; 33: 2225-2231.

2. Chimen M, Kennedy A, Nirantharakumar K, Pang TT, Andrews $R$, Narendran P. What are the health benefits of physical activity in Type 1 diabetes mellitus? A literature review. Diabetologia 2012 55: 542-551.

3. Hood T, Lalantha L. Basal insulin delivery reduction for exercise in Type 1 diabetes: finding the sweet spot. Diabetologia 2016; 59: 1628-1631.
4. Thorell A, Hirshman MF, Nygren J, Jorfeldt I, Wojtasewski JF, Dufresne SD, et al. Exercise and insulin cause GLUT-4 translocation in human skeletal muscle. Am J Physiol1999; 277: E733-E741.

5. Taiwo EO, Akindele RA, Adefuye BO, Sofola OA, Fasanmade AA, Oyebola DDO, et al. Total Cholesterol and HDL ratio in normoglycaemic offspring of patients with T2DM on graded exercise. World J Pharm Med Res 2017; 3(10): 3035.

6. Rönnemaa T, Koivisto VA. Combined effect of exercise and ambient temperature on insulin absorption and postprandial glycemia in Type 1 patients. Diabetes Care 1988; 11: 769773.

7. Marliss EB, Vranic M. Intense exercise has unique effects on both insulin release and its roles in glucoregulation: implications for diabetes. Diabetes 2002; 51(Suppl 1): S271-S83.

8. Skleryk JR, Karagounis LG, Hawley JA, Sharman MJ, Laursen PB. Two weeks of reduced-volume sprint interval or traditional exercise training does not improve metabolic functioning in sedentary obese men. Diabetes Obes Metab 2013; 15: 1146-1153.

9. Conn VS, Koopman RJ, Ruppar TM, Phillips LJ, Mehr DR, Hafdhal AR. Insulin sensitivity following exercise interventions: systematic review and meta-analysis of outcomes among healthy adults. J Prim Care Comm Health 2014; 27: 211-222.

10. Grieco CR, Swain DP, Colberg SR, Dowling EA, Baskette K, Zarrabi I, et al. 
Taiwo EO, et al.

Effect of intensity of aerobic training on insulin sensitivity/resistance in recreationally active adults. J Strength Cond Res 2013; 27: 2270-2276.

11. Chen $\mathrm{CN}$, Chuang LM, Korivi M, Wu YT. Home-based exercise may not decrease insulin resistance in individuals with metabolic syndrome. J Phys Act Health 2015; 12: 74-79.

12. Malin SK, Haus JM, Solomon TP, Blaszczak A, Kashyap SR, Kirwan JP. Insulin sensitivity and metabolic flexibility following exercise training among different obese insulin-resistant phenotypes. Am J Physiol Endocrinol Metab 2013; 305: E1292-E129. cited and credited. 